\title{
Determinants of Adherence with Malaria Chemoprophylactic Drugs Used in a Traveler's Health Clinic
}

\author{
Ibrahim Shady \\ Community Medicine Department, Faculty of Medicine, Mansoura University, Mansoura 35516, Egypt \\ Correspondence should be addressed to Ibrahim Shady; ebrshady@hotmail.com
}

Received 20 March 2015; Revised 20 May 2015; Accepted 26 May 2015

Academic Editor: Marcel Tanner

Copyright (c) 2015 Ibrahim Shady. This is an open access article distributed under the Creative Commons Attribution License, which permits unrestricted use, distribution, and reproduction in any medium, provided the original work is properly cited.

Background. The WHO recommends mefloquine, atovaquone/proguanil, and doxycycline for malaria chemoprophylaxis. Adherence to a drug is determined by many factors. Objective. To detect the determinants of travelers' adherence to malaria chemoprophylaxis. Methods. A prospective comparative study was conducted from January 2012 to July 2013 that included travelers (928 travelers) to malaria endemic countries who visited the THC. They were classified into 3 groups: the 1st is the mefloquine group (396 travelers), the 2 nd is the doxycycline group (370 travelers), and finally those who did not receive any drugs (162 travelers). The participants from the 1st and 2nd groups enrolled in the study. Results. Univariate and multivariate analyses were performed. The predictors for adherence in the mefloquine group were travel to an African destination [OR $=51$ (6.8-2385)], higher than a secondary school education $[\mathrm{OR}=21(4.1-144.2)]$, organized travel $[\mathrm{OR}=4(2.1-6.5)]$, traveling for leisure $[\mathrm{OR}=2.1(1.1-0.4)]$, and nationality $[\mathrm{OR}=2(1.11-4.00)]$. In the doxycycline group, the predictors included higher than a secondary education $[\mathrm{OR}=20.1$ (4.5-125.1)], organized travel [OR $=11.4(5.5-20.9)]$, travel for leisure [OR $=7$ (2.3-22.9)], travel to an African destination [OR = $6.1(0.41-417)]$, and nationality [OR $=4.5(2.3-9.5)]$. Conclusion. Adherence with malaria chemoprophylaxis could be affected by many factors such as nationality, education, and organized travel.

\section{Background}

Malaria is an important threat to tourists, employees, and international travelers traveling or working in endemic areas due to the potentially rapid onset of infection and the severity of the disease. International travelers should be protected from malaria by chemoprophylaxis and prophylactic measures against mosquito bites. Chemoprophylaxis is a key component of malaria prevention because none of the vector protection measures completely protect against mosquito bites during night time activities. However, the effectiveness of chemoprophylaxis is limited by lack of compliance with drug intake [1-3].

Malaria chemoprophylaxis has been shown to have a low cost-benefit ratio compared to other prophylactic interventions for travelers [4], and several studies have suggested that increased risks of malaria may occur in noncompliant travelers [5-8]. Among travelers to endemic areas, compliance regarding malaria chemoprophylaxis is generally poor, ranging from 32 to $74 \%$ depending on the definitions used $[9,10]$.

Risk factors that predict noncompliance are important, as they may be used to increase compliance by improving pretravel information. Such risk factors have been studied among European and North American travelers on return flights from Kenya and several West African countries and have included young age, longer travel duration, previous travel to tropical destinations, visits to friends or family as the travel purpose, occurrence of adverse reactions, and use of the drugs $[11,12]$.

Kuwait is considered a high income country, and its inhabitants commonly travel during the summer period due to hot weather, as the temperature may reach as high as $50^{\circ} \mathrm{C}$. Malaria is not endemic in Kuwait but, with a large expatriate 
population, the number of imported infections increased every year compared with the increased number of recruiting expatriates. However, malaria infection risk is still very low due to the absence of the vector for malaria transmission $[13,14]$.

Only one traveler's health clinic is available in Kuwait to provide travel health services, which include immunizations, chemoprophylaxis for malaria, and health advice/information about the prevalent diseases/health hazards in the destination country [15].

Two drugs are used for malaria chemoprophylaxis. These drugs include mefloquine hydrochloride (250 mg tab) (generic: mefloquine or lariam), which is given on weekly basis (i.e., every week starting one week before travel and completed at least 4 weeks after leaving the malaria endemic area), and doxycycline (100 mg caps) (generic: vibramycin or doxydar), which is given on daily basis (i.e., one capsule every day starting one day before travel and completed 4 weeks after leaving the malaria endemic area) [16-20].

Many studies have been conducted to identify factors that influence compliance with medications, most of which have focused on treatments to cure, the ability to reduce or delay complications and symptoms caused by chronic diseases. Only a few studies have assessed compliance in the context of chemoprophylaxis. Recently, the concept of adherence has supplanted compliance, as adherence implies that the patient agrees with the prescribed recommendations rather than passively obeying them [11].

The main objectives of this study are to explore the determinants and risk factors affecting the adherence of travelers visiting the THC to malaria chemoprophylactic drugs.

\section{Subjects and Methods}

Our study is a prospective comparative (analytical) study that included all travelers to malaria endemic areas who visited the THC (928 travelers) to obtain malaria prophylaxis. The study period was from January 2012 to July 2013.

We interviewed 928 travelers who visited the THC to receive their malaria chemoprophylaxis. They consisted of Kuwaitis and residents from other nationalities, mainly Egyptians and Indians, to lesser extent Arabians other than Egyptians, Europeans, Americans, and Asians, and rarely those from South and West African countries. This was consistent with the population demography in Kuwait [21, 22].

All of the 928 travelers were classified on the basis of malaria chemoprophylactic drugs into 3 groups: the 1st group consisted of travelers who received mefloquine (396 travelers, $42.7 \%$ ), the 2 nd group consisted of travelers who received doxycycline (370 travelers, 39.9\%), and the last group consisted of travelers who refused to receive malaria drugs or had contraindications to the drugs (162 travelers, $17.5 \%)$. The choice of drug was based on many factors, including the traveler's health status, past history of taking the drug without problems, contraindications, and the traveler's decision as reported by Senn et al., 2007, who reported many causes behind travelers' choice of malaria chemoprophylactic drug and the factors that influenced their final decision [19].

Malaria chemoprophylactic drugs were given to all travelers free of charge according to the rules set by the managing department.

All travelers enrolled on this study were interviewed by the same travel health team (physician and/or nurse) and asked to complete a predeparture health questionnaire [20] that included sociodemographic data that consisted of contact information (mobiles, landlines, and emails), travel journey data, and malaria prophylactic drugs.

Fortunately, Kuwait has well-developed communication infrastructure which is cheap and widespread. This communication system enables nearly all of its inhabitants to have more than one mean of communications (emails, mobiles, and landlines). The government holds the control over the landline system which is provided with accepted annual fees for the subscribers. In addition, there are three large mobile providing companies that provide mobile lines in reasonable fees covering all over the country. Also, Internet access is available and it is widely distributed.

We used mobile lines as the first line of communication, followed by landlines and then the Internet. Luckily, most of travelers responded to the mobile contact which is used by some researchers for monitoring the malaria and its treatment [23].

We contacted all of the 766 travelers (there were no defaulters or drop-out cases) who obtained malaria chemoprophylaxis twice after their return (after the 1st week and at the end of the 4 th week after their return). They were asked about the regularity with which they took the drug during and after their return. Only those who answered "no" were subjected to another set of questions to determine the factors related to their nonadherence.

Adherence to the chemoprophylaxis regimen was recorded retrospectively according to self-reported use and defined as regular and uninterrupted use of both drugs until the posttravel communication with the travelers [18].

The operational definition of regular and uninterrupted use was not having missed more than one day dose per week on average for the daily dose drug and not having missed any dose of the weekly dose drug. However, the term adherence has recently supplanted compliance, as adherence implies that the patient agrees with the prescribed recommendations rather than passively obeying them [11].

We designed two versions of the questionnaire (Arabic and English). Individuals below 6 years of age were helped by their parents or older brothers/sisters, and individuals who could not understand or complete the questionnaire were assisted in its completion.

Informed consent was obtained from every individual in this study. We obtained approval to conduct our study from the ethical and approval committee of Traveler's Health Board and the head of the department.

The terms adherence and compliance were used interchangeably in this study as compliance constitutes an element of adherence. 
2.1. Date Collection and Analyses. Data were collected and analyzed using SPSS for Windows version 17.0 (SPSS, Chicago, IL). Continuous data are expressed as the mean \pm $\mathrm{SD}$. Comparisons of the continuous data between the two groups were performed using independent Student's $t$-tests. All categorical data are expressed in number and percent and were compared between the two groups using Pearson's and Fisher's exact $\chi^{2}$ tests. The $95 \%$ confidence intervals (CI) for the differences in means were calculated. Statistical significance was set at $p<0.05$. Multivariate analysis was performed to determine the factors that affect adherence to the drug regimens, and the variables of the multivariate analysis were selected from the most significant variables in the univariate analysis.

\section{Results and Comments}

The sociodemographic and travel-related data of the 928 subjects enrolled initially in this study were obtained and are described in Table 1, which shows that males represent slightly less than $2 / 3$ of individuals in the groups that received mefloquine (group 1) and doxycycline (group 2), but this proportion was inverted for the no chemoprophylaxis group (group 3). Nonnationals represented approximately $60 \%$ of the 3 groups. Most travelers in groups 1 and 2 were educated above the secondary level; however, for the 3rd group, postgraduate education was higher. Most of the travelers in the 3 groups were working ( $80.8 \%$ to $87.7 \%$ ). Many people were travelling for leisure purposes (59.6\% to $70.4 \%$ ) followed by work purposes and then for family visits. Organized trips were more prevalent than independent trips. African countries were the destination of choice for groups 1,2 , and 3 (73.7\%, 78.4\%, and 59.3\%, resp.), followed by Asian countries and Latin countries. The mean age of the travelers was between 32 and 38.5 years, and the mean travel duration was 3.5 to 4.1 weeks.

3.1. Use of Chemoprophylaxis and Adherence. Of the 928 subjects initially enrolled on the study, only $82.5 \%$ obtained the chemoprophylactic drugs against malaria, and these individuals were classified into 2 groups; the 1st group was the mefloquine group, and the 2nd group was the doxycycline group. The rates of nonadherence for groups 1 and 2 were $18.4 \%$ and $20.5 \%$, respectively [Figure 1]. In the 1st group, most of the nonadherence occurred after finishing travel (27.4\% dropped out after the 1st week and 28.8\% dropped out after the 4 th week) as opposed to the 2 nd group (13.2\% dropped out after the 1st week and $14.5 \%$ dropped out after the 4 th week), and the differences were statistically significant $(p=0.03)$. However, a larger proportion of the second group dropped out during travel (32.9\%) in contrast to the 1st group $(6.8 \%)$, and the difference was highly statistically significant $(p=0.0001)$.

3.2. Factors Affecting Adherence to Malaria Chemoprophylaxis. Tables 3 and 4 show the univariate analysis of adherence for the mefloquine and doxycycline groups with the risk

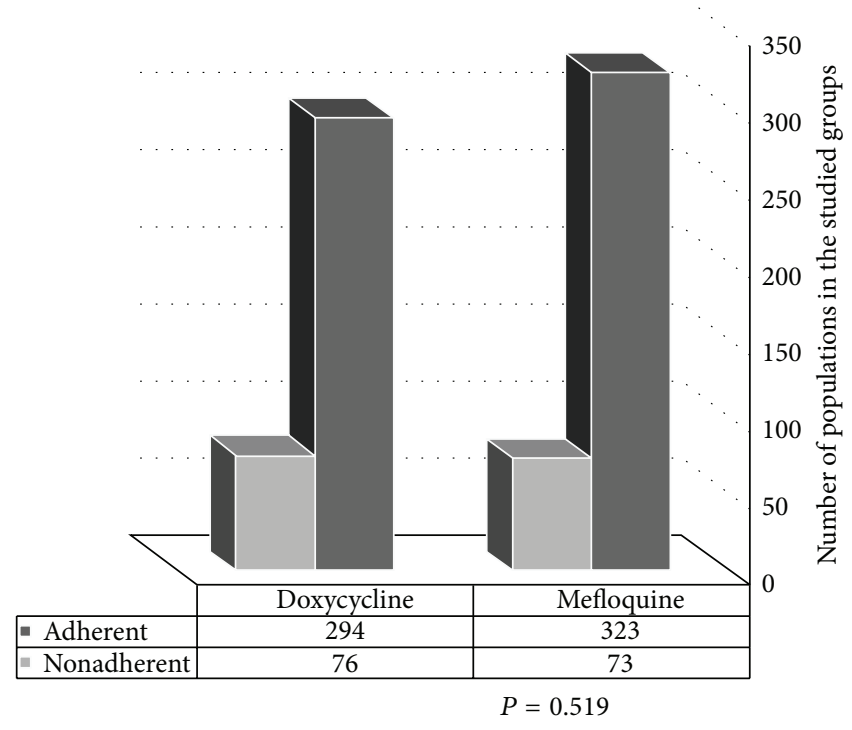

FIGURE 1: Comparison between the mefloquine and doxycycline groups according to adherence.

factors of interest. Some risk factors were significantly associated with nonadherence in both groups. Nationality significantly affected the degree of adherence, specifically by 2.25 fold in group 1 and 5.1-fold in group 2. Regarding education, after using noneducated individuals as a reference value for comparison, we found that the level of education maximally affected the degree of adherence for individuals with higher than a secondary level of education (24.6- and 22.3-fold for group 1 and group 2, resp.), and the differences were statistically significant $(p=0.0001)$. However, nonadherence was maximal among university educated individuals in groups 1 and 2 (27.4\% and 30.3\%, resp.), and the differences were statistically significant $(p=0.005)$. Regarding occupation, after using the nonworking group as a reference value for comparison, we found that nonadherence was increased among blue collar workers for groups 1 and 2 (35.6\% and $25 \%$, resp.) and the differences were statistically significant $(p=0.0001)$. Additionally, the domestic helper occupation category showed significant nonadherence tendencies in both groups. Traveling for leisure was a very important factor in determining adherence in groups 1 and $2(71.8 \%$ and $67.7 \%$, resp., $p=0.0001$ ). Additionally, travel that was organized by an agent affected the tendency for adherence more than travel that was arranged independently, and the difference was statistically significant for both groups $(p=0.0001)$. Travel destination to African countries was a significant factor for adherence and compliance to the drug and its dosing for the complete regimen and produced 53-fold higher adherence for the mefloquine group (group 1) and 8.6-fold higher adherence for the doxycycline group (group 2). The travel duration was also a significant factor for adherence to the given drug ( $p=0.0001)$.

Table 5 shows the multivariate analysis for selected risk factors that predicted good adherence for both groups. We 
TABLE 1: Sociodemographic characteristics of the studied groups.

\begin{tabular}{|c|c|c|c|c|c|c|}
\hline \multirow{2}{*}{ Characteristic } & \multicolumn{2}{|c|}{ Mefloquine group } & \multicolumn{2}{|c|}{ Doxycycline group } & \multicolumn{2}{|c|}{ No chemoprophylaxis } \\
\hline & $N$ & $(\%)$ & $N$ & $(\%)$ & $N$ & $(\%)$ \\
\hline Total $=928(100)$ & 396 & 100 & 370 & 100 & 162 & 100 \\
\hline \multicolumn{7}{|l|}{ Sex } \\
\hline Male & 247 & 62.4 & 231 & 62.4 & 71 & 43.8 \\
\hline Female & 149 & 37.6 & 139 & 37.6 & 91 & 56.2 \\
\hline \multicolumn{7}{|l|}{ Nationality } \\
\hline Non-Kuwaiti & 241 & 60.9 & 222 & 60.0 & 101 & 62.3 \\
\hline Kuwaiti & 155 & 39.1 & 148 & 40.0 & 61 & 37.7 \\
\hline \multicolumn{7}{|l|}{ Education } \\
\hline Not educated & 11 & 2.8 & 15 & 4.1 & 5 & 3.1 \\
\hline Primary, secondary & 89 & 22.5 & 78 & 21.1 & 32 & 19.8 \\
\hline Above secondary & 159 & 40.2 & 122 & 33.0 & 35 & 21.6 \\
\hline University & 73 & 18.4 & 59 & 16.0 & 12 & 7.4 \\
\hline Postgraduate & 64 & 16.2 & 96 & 26.0 & 81 & 50 \\
\hline \multicolumn{7}{|l|}{ Occupation } \\
\hline Not working & 73 & 18.4 & 71 & 19.2 & 20 & 12.3 \\
\hline White collar & 189 & 47.7 & 2.3 & 54.9 & 88 & 54.3 \\
\hline Blue collar & 57 & 14.4 & 33 & 8.9 & 21 & 13 \\
\hline Domestic helper & 77 & 19.4 & 63 & 17 & 33 & 20.4 \\
\hline \multicolumn{7}{|l|}{ Travel purpose } \\
\hline Leisure & 236 & 59.6 & 242 & 65.4 & 114 & 70.4 \\
\hline Family visit & 52 & 13.1 & 28 & 7.6 & 12 & 7.4 \\
\hline Work & 108 & 27.3 & 100 & 27 & 36 & 22.2 \\
\hline \multicolumn{7}{|l|}{ Travel style } \\
\hline Independent & 120 & 30.3 & 96 & 25.9 & 36 & 22.2 \\
\hline Organized & 276 & 69.7 & 274 & 74.1 & 126 & 77.8 \\
\hline \multicolumn{7}{|l|}{ Destination } \\
\hline Africa & 292 & 73.7 & 290 & 78.4 & 96 & 59.3 \\
\hline Asia & 96 & 24.2 & 77 & 20.8 & 24 & 14.8 \\
\hline \multirow[t]{2}{*}{ South America } & 8 & 2.1 & 3 & 0.8 & 42 & 25.9 \\
\hline & Mean & $\mathrm{SD}$ & Mean & SD & Mean & $\mathrm{SD}$ \\
\hline Age (years) & 38.5 & 11.9 & 37.5 & 12.4 & 32.6 & 13.2 \\
\hline Travel duration (W) & 4.0 & 1.0 & 4.1 & 1.2 & 3.5 & 1.1 \\
\hline
\end{tabular}

TABLE 2: Nonadherence types among the studied groups.

\begin{tabular}{|c|c|c|c|c|}
\hline Types of nonadherence & Mefloquine group & Doxycycline group & $P$ value & $\mathrm{OR} \pm 95 \mathrm{CI}$ \\
\hline Not started & $12(16.4)$ & $5(6.6)$ & 0.05 & \\
\hline Irregular use & $15(20.5)$ & $25(32.9)$ & 0.08 & $052 \pm(0.25-1.11)$ \\
\hline Dropped during travel & $5(6.8)$ & $25(32.9)$ & 0.0001 & $0.5 \pm(0.05-0.4)$ \\
\hline Dropped after 1st week of return & $20(27.4)$ & $10(13.2)$ & 0.03 & $2.5 \pm(1.1-2.9)$ \\
\hline Dropped after 4 th week of return & $21(28.8)$ & $11(14.5)$ & 0.03 & $2.4 \pm(1.1-5.5)$ \\
\hline Total & $73(100)$ & $76(100)$ & & $149(100)$ \\
\hline
\end{tabular}


TABLE 3: Univariate analysis of mefloquine group between adherent and nonadherent individuals.

\begin{tabular}{|c|c|c|c|c|c|c|}
\hline \multirow{2}{*}{ Characteristic } & \multicolumn{2}{|c|}{ Nonadherent } & \multicolumn{2}{|c|}{ Adherent } & \multirow{2}{*}{$P$ value } & \multirow{2}{*}{$\mathrm{OR} \pm 95 \mathrm{CI}$} \\
\hline & $N$ & $(\%)$ & $N$ & (\%) & & \\
\hline Total $=149(100)$ & 73 & 100 & 323 & 100 & & \\
\hline \multicolumn{7}{|l|}{ Sex } \\
\hline Male & 45 & 61.7 & 202 & 62.5 & \multirow[t]{2}{*}{0.4} & \multirow[t]{2}{*}{$0.96(0.57-1.63)$} \\
\hline Female & 28 & 38.3 & 121 & 37.5 & & \\
\hline \multicolumn{7}{|l|}{ Nationality } \\
\hline Non-Kuwaiti & 55 & 75.3 & 186 & 57.6 & \multirow[t]{2}{*}{0.002} & \multirow[t]{2}{*}{$2.25(1.28-4.08)$} \\
\hline Kuwaiti & 18 & 24.7 & 137 & 42.4 & & \\
\hline \multicolumn{7}{|l|}{ Education } \\
\hline Not educated $^{*}$ & 8 & 11 & 3 & 0.9 & & \\
\hline Primary, secondary & 17 & 23.3 & 72 & 22.3 & 0.0005 & $10.9(2.32-70.6)^{\#}$ \\
\hline Above secondary & 15 & 20.5 & 144 & 44.6 & 0.0001 & $24.6(5.23-159.3)^{\#}$ \\
\hline University & 20 & 27.4 & 53 & 16.4 & 0.005 & $6.87(1.46-44.3)^{\#}$ \\
\hline Postgraduate & 13 & 17.8 & 51 & 15.8 & 0.001 & $10.3(2.43-45.04)^{\#}$ \\
\hline \multicolumn{7}{|l|}{ Occupation } \\
\hline Not working ${ }^{*}$ & 6 & 8 & 67 & 20.7 & & \\
\hline White collar & 25 & 34.2 & 164 & 50.8 & 0.13 & $0.6(0.21-1.44)$ \\
\hline Blue collar & 26 & 35.6 & 31 & 9.5 & 0.0001 & $0.11(0.04-0.28)$ \\
\hline Domestic helper & 16 & 21.9 & 61 & 18.9 & 0.01 & $0.34(0.12-0.92)$ \\
\hline \multicolumn{7}{|l|}{ Travel purpose } \\
\hline Family visit ${ }^{*}$ & 18 & 24.7 & 34 & 10.5 & & \\
\hline Leisure & 34 & 46.6 & 232 & 71.8 & 0.0001 & $3.6(1.8-7.1)$ \\
\hline Work & 21 & 28.8 & 87 & 26.9 & 0.01 & $2.18(1.03-4.63)$ \\
\hline \multicolumn{7}{|l|}{ Travel style } \\
\hline Independent & 43 & 58.9 & 77 & 23.8 & \multirow[t]{2}{*}{0.0001} & \multirow[t]{2}{*}{$4.6(2.7-7.8)$} \\
\hline Organized & 30 & 41.1 & 246 & 76.2 & & \\
\hline \multicolumn{7}{|l|}{ Destination } \\
\hline South America* & 7 & 9.5 & 1 & 0.3 & & \\
\hline Asia & 33 & 45.2 & 63 & 19.5 & 0.004 & $13.05(1.57-611.5)^{\#}$ \\
\hline \multirow[t]{2}{*}{ Africa } & 33 & 45.2 & 259 & 80.2 & 0.0001 & $53.6(7.96-2485)^{\#}$ \\
\hline & Mean & SD & Mean & SD & $t$-test & \\
\hline Age (years) & 38.5 & 11.9 & 42.6 & 10.3 & 0.003 & \\
\hline Travel duration (W) & 4.0 & 1.0 & 5.2 & 1.1 & 0.0001 & \\
\hline
\end{tabular}

${ }^{*}$ Reference value for comparison.

${ }^{\#}$ Fisher's exact test (chi square).

found that predictors of good adherence for the mefloquine group included travel to an African destination, education above a secondary level, organized travel, traveling for leisure, and Kuwaiti nationality.
However, in the doxycycline group, the predictors included higher than a secondary level of education, followed by organized travel, and then travel for leisure, travel to an African destination, and Kuwaiti nationality. 
TABLE 4: Univariate analysis of doxycycline group between adherent and nonadherent individuals.

\begin{tabular}{|c|c|c|c|c|c|c|}
\hline \multirow{2}{*}{ Characteristic } & \multicolumn{2}{|c|}{ Nonadherent } & \multicolumn{2}{|c|}{ Adherent } & \multirow{2}{*}{$P$ value } & \multirow{2}{*}{$\mathrm{OR} \pm 95 \mathrm{CI}$} \\
\hline & $N$ & $(\%)$ & $N$ & $(\%)$ & & \\
\hline Total = $396(100)$ & 76 & 100 & 294 & 100 & & \\
\hline \multicolumn{7}{|l|}{ Sex } \\
\hline Male & 53 & 69.7 & 178 & 60.5 & \multirow{2}{*}{0.07} & \multirow{2}{*}{$1.5(0.87-1.61)$} \\
\hline female & 23 & 30.1 & 116 & 39.5 & & \\
\hline \multicolumn{7}{|l|}{ Nationality } \\
\hline Non-Kuwaiti & 65 & 85.5 & 157 & 53.4 & \multirow{2}{*}{0.0001} & \multirow[t]{2}{*}{$5.1(2.66-10.58)$} \\
\hline Kuwaiti & 11 & 14.5 & 137 & 46.6 & & \\
\hline \multicolumn{7}{|l|}{ Education } \\
\hline Not educated* & 12 & 15.8 & 3 & 1.0 & & \\
\hline Primary, secondary & 16 & 21.1 & 62 & 21.1 & 0.0001 & $14.9(3.5-92.1)^{\#}$ \\
\hline Above secondary & 18 & 23.7 & 104 & 35.4 & 0.0001 & $22.3(5.33-135.1)^{\#}$ \\
\hline University & 23 & 30.3 & 36 & 12.2 & 0.004 & $6.1(1.4-37.4)^{\#}$ \\
\hline Postgraduate & 7 & 9.2 & 89 & 30.3 & 0.0001 & $46.9(9.9-320.7)^{\#}$ \\
\hline \multicolumn{7}{|l|}{ Occupation } \\
\hline Not working* & 10 & 13.2 & 61 & 20.7 & & \\
\hline White collar & 20 & 26.3 & 183 & 63.3 & 0.2 & $1.5(0.63-3.35)$ \\
\hline Blue collar & 19 & 25 & 14 & 4.8 & 0.0001 & $0.12(0.05-0.32)$ \\
\hline Domestic helper & 27 & 35.5 & 36 & 12.2 & 0.0001 & $0.22(0.09-0.5)$ \\
\hline \multicolumn{7}{|l|}{ Travel purpose } \\
\hline Family visit ${ }^{*}$ & 21 & 27.6 & 7 & 2.4 & & \\
\hline Leisure & 43 & 56.6 & 199 & 67.7 & 0.0001 & $13.7(5.6-36.6)$ \\
\hline Work & 12 & 15.8 & 88 & 29.9 & 0.0001 & $21.1(7.6-64.3)$ \\
\hline \multicolumn{7}{|l|}{ Travel style } \\
\hline Independent & 52 & 68.4 & 44 & 15.0 & \multirow[t]{2}{*}{0.00001} & \multirow[t]{2}{*}{$12.2(6.9-22.1)$} \\
\hline Organized & 24 & 31.6 & 250 & 85.0 & & \\
\hline \multicolumn{7}{|l|}{ Destination } \\
\hline South America* & 2 & 2.6 & 1 & 0.3 & & \\
\hline Asia & 20 & 26.3 & 57 & 19.4 & 0.06 & $5.6(0.27-343)^{\#}$ \\
\hline \multirow[t]{2}{*}{ Africa } & 54 & 71.1 & 236 & 80.3 & 0.09 & $8.6(0.44-517.1)^{\#}$ \\
\hline & Mean & $\mathrm{SD}$ & Mean & SD & $t$-test & \\
\hline Age (years) & 37.5 & 12.4 & 40.6 & 9.6 & 0.02 & \\
\hline Travel duration (W) & 4.1 & 1.2 & 5.0 & 1.2 & 0.0001 & \\
\hline
\end{tabular}

* Reference value for comparison.

\#Fisher's exact test (chi square).

TABLE 5: Multivariate analysis of some risk factors in both groups.

\begin{tabular}{|c|c|c|c|c|}
\hline \multirow{3}{*}{ Variables } & \multicolumn{4}{|c|}{ Group } \\
\hline & \multicolumn{2}{|c|}{ Mefloquine group } & \multicolumn{2}{|c|}{ Doxycycline group } \\
\hline & Adj. OR & $P$ & Adj. OR & $P$ \\
\hline Kuwaiti nationality & $2(1.11-4.0)$ & $<0.05$ & $4.5(2.3-9.5)$ & $<0.001$ \\
\hline Above secondary & $21(4.1-144.2)$ & $<0.001$ & $20.1(4.5-125.1)$ & $<0.001$ \\
\hline White collars & $0.11(0.04-0.33)$ & $>0.05$ & $1(0.5-2.1)$ & $>0.05$ \\
\hline Leisure travel & $2.1(1.1-3.4)$ & $<0.05$ & $7(2.3-22.9)$ & $<0.05$ \\
\hline Organized travel & $4(2.1-6.5)$ & $<0.05$ & $11.4(5.5-20.9)$ & $<0.001$ \\
\hline African destination & $51(6.8-2385)$ & $<0.001$ & $6.1(0.41-417)$ & $=0.05$ \\
\hline
\end{tabular}




\section{Discussion}

This study identified both collective and individual determinants of correct adherence to malaria chemoprophylaxis among individuals travelling to malaria endemic areas and visiting the THC during the period from January 2012 to July 2013.

4.1. Use of Chemoprophylaxis and Adherence. Of the 928 subjects initially enrolled on the study, only $82.5 \%$ received chemoprophylactic drugs against malaria due to many factors such as refusing to take the antimalarial drugs due to bad previous experience and/or contraindications to the drugs $[19,24,25]$. Individuals who received the drugs were classified into 2 groups; the 1st group was the mefloquine group, and the 2nd group was the doxycycline group (Table 2).

The rate of adherence for groups 1 and 2 was $81.6 \%$ and $79.5 \%$, respectively, as shown in Figure 1. This rate is higher than that reported in the study by Frank G. J. and Anne L. K. (1991-1992), which examined adherence to malaria chemoprophylaxis among Dutch travelers [26] and reported an overall adherence of $59 \%$. This difference may be due to differences in the types of subjects enrolled in the study, as we enrolled all individuals who visited the THC for travel health advice and measures; however, the Dutch study was a part of larger cohort study of health risks among travelers. In addition, our adherence results were higher than those reported by other studies [26-33]. In our study the rates of nonadherence to both drugs were nearly the same which might be due to travelers' beliefs that they had a lower risk of malaria infection on returning to Kuwait due to the fact that malaria is not endemic in Kuwait [14]. Other causes that lead to nonadherence included simply forgetting, fear of long term side effects, discontinuation due to occurrence of unpleasant side effects [such as neuropsychiatric (nightmares, vivid dreams, anxiety, insomnia, and depression), gastrointestinal (heart burns, colic, nausea, and vomiting), and musculoskeletal (easy fatigability, muscle pains, and lassitude)], and busy life style.

In the 1st group, most of the nonadherence occurred after finishing travel (27.4\% dropped out after the 1st week and $28.8 \%$ dropped out after the 4 th week) in contrast to the 2 nd group (13.2\% dropped out after the 1st week and $14.5 \%$ dropped out after the 4th week), and the differences were statistically significant $(p=0.03)$. However, for the second group, more individuals dropped out during travel $(32.9 \%)$ than in the 1st group (6.8\%), and the difference was highly statistically significant $(p=0.0001)$. Our results regarding the mode of nonadherence are much lower than those reported by the Dutch study [26], which indicated that half of all noncompliance was due to early discontinuation after return. More than half of the travelers had stopped their chemoprophylaxis because they found that it was unnecessary to continue the treatments. However, in our study, the lower rate of nonadherence as well as the lower rate of discontinuation, either early or late after return, may be attributed to the travel-related information provided to the travelers during their visits to the THC. Nonadherent individuals reported that they found it inconvenient to continue to take the medications for 4 weeks after return due to their busy schedules. Others believed that they were not exposed to malaria during their travels; however, some individuals experienced unpleasant side effects, as reported in some studies [24, 25].

\subsection{Factors Affecting Adherence to Malaria Chemoprophy-} laxis. A univariate analysis was conducted to determine which factors affect the traveler's adherence to the chemoprophylactic drugs (mefloquine group, Table 3, and doxycycline group, Table 4).

Tables 3 and 4 show the factors of both groups of travelers. Nationality increases the degree of adherence in both groups (by 2.25-fold in the mefloquine group and 5.1-fold in the doxycycline group) which could be attributed to the fact that some non-Kuwaiti individuals usually travel during the holidays to their home countries and they believe that they are not at risk for acquiring malaria. The nationality of the travelers affected the adherence rate through factors such as the belief that malaria is not endemic in the country due to the absence of the vector transmitting it. So, Kuwaitis tended to be nonadherent especially when they return to their home country. Non-Kuwaitis who come from areas where malaria is endemic know the impact of malaria on their health as well as the long duration of treatment so their adherence rate is higher. Non-Kuwaitis from developed countries have a high amount of health information about travel-related health hazards leading them to be more adherent.

Education significantly affected the degree of adherence for both groups, and the maximum difference was observed in individuals with higher than a secondary level of education (24.6-fold and 22.3-fold); however, a university level of education significantly increased the degree of nonadherence in both groups. This could be because those educated above secondary level usually adhere to advice to take a drug due to their psychological condition regarding their health. Also, those educated above secondary level showed an increased level of awareness of antimalarial chemoprophylaxis, which served to motivate them to adhere to the prescribed drug regimens. However, individuals with a university level of education had enormous information regarding the destination, drug, and disease, which helped them to decide whether to follow or not follow our advice. In contrast to our results, Gagneux et al., 1996 [34], found no association between the adherence and the degree of education. Employment status also affected the degree of adherence in both groups, as adherence was insignificantly high among white collar workers in both groups. However, nonadherence was significantly higher among blue collar workers in both groups, which could be because white collar workers are usually highly educated (at least above the secondary level). However, blue collar workers usually do not complete their education level to a secondary level. Degree of adherence among domestic helpers usually is affected by the degree of adherence of their sponsors as they usually accompany their sponsors during their vacations so they usually follow their mode of adherence as well as the type of prophylaxis they got.

Travel for the purpose of leisure significantly affected the degree of adherence in both groups, which could be 
attributed to the fact that leisure travelers tended to go on safari and other travel-related adventures such as visiting wild life fields and forests and climbing mountains. They believed that these adventures are risky because they occur in open places; therefore, they likely tend to be more compliant than others. In organized travel, where travelers are on an organized trip, they are more likely to be adherent. Similar results were identified in the Dutch study in 1997 [26]. This could be explained because group travelers (organized tours) usually stimulate and encourage all participants to be compliant by social stimulation [26]. Another explanation is that organized tours are usually conducted by highly experienced tourist companies, and they obtain all of the health education materials that contain the risks of the travel destination and how they could be prevented. These companies disseminate this information to their travelers. Travel destinations in Africa significantly promoted adherence in both groups because most travelers to these areas are aware that malaria in African countries is highly endemic and is evenly distributed; therefore, the malaria risk for travelers is the highest in the world $[9,12]$, which encouraged the high adherence reported in this study. Additionally, travelers to African countries are usually exposed to travel-related hazards as they go on safari, visit open zoos, climb mountains, and live in camps and tents. They believe that such activities increase their risk of getting malaria because they occur in open places. To a lesser extent, travelers believe that the degree of health care in these countries is not high and this makes them more adherent. Also, most trips to African destinations were organized by travel agencies that ask every traveler to provide proof of malaria chemoprophylaxis as a prerequisite for getting an entrance visa. Similar results were reported by other studies [11,20]. Age $>40$ years and travel duration $\geq 5$ weeks encouraged travelers to be more compliant, and similar results were reported in other studies $[11,12,26]$.

Predictors of good adherence for both groups included five factors that differed in the order and strength for both groups. However, our results are very similar to those of the Dutch study [26]. This study provided valuable information for designing plans to increase adherence for those with a lower adherence rate and to strengthen adherence among those with higher rates of adherence.

\section{Conclusion and Recommendations}

Adherence with malaria chemoprophylaxis could be affected by many risk factors such as education, organized travel, leisure travel, and travel destination, as well as the duration of travel and the age of traveler. Therefore, adherence with malaria chemoprophylaxis should be improved in travelers to areas with high risks of malaria infection by designing health education programs that must be provided to those travelers in many occasions and periodically.

Travelers' health education programs should be designed with special emphasis on the need for a clear conveyance of the importance of continuing chemoprophylaxis.

Additionally, new methods of traveler education need to be developed and should be based on data from in-depth studies of travelers' motivations to take preventative measures.

Extra attention should be given to young, independent travelers and to those who have been found to show a low rate of adherence and may underestimate their risk of malaria on the basis of their thoughts and beliefs.

\section{Conflict of Interests}

The author declares that there is no conflict of interests regarding the publication of this paper.

\section{References}

[1] World Health Organization, Fact Sheet Malaria, World Health Organization, 2011, http://www.who.int/mediacentre/ factsheets/fs094/en/.

[2] M. Henry, I. Diallo, J. Bordes et al., "Urban malaria in Dakar, Senegal: chemosusceptibility and genetic diversity of Plasmodium falciparum isolates," The American Journal of Tropical Medicine and Hygiene, vol. 75, no. 1, pp. 146-151, 2006.

[3] B. Pradines, P. Hovette, T. Fusai et al., "Prevalence of in vitro resistance to eleven standard or new antimalarial drugs among Plasmodium falciparum isolates from Pointe-Noire, Republic of the Congo," Journal of Clinical Microbiology, vol. 44, no. 7, pp. 2404-2408, 2006.

[4] R. H. Behrens and J. A. Roberts, "Is travel prophylaxis worth while? Economic appraisal of prophylactic measures against malaria, hepatitis A, and typhoid in travellers," British Medical Journal, vol. 309, no. 6959, pp. 918-922, 1994.

[5] H. O. Lobel, J. M. Roberts, B. Somaini, and R. Steffen, "Efficacy of malaria prophylaxis in American and Swiss travelers to Kenya," The Journal of Infectious Diseases, vol. 155, no. 6, pp. 1205-1209, 1987.

[6] T. W. Gyorkos, J. E. Svenson, J. D. MacLean, N. Mohamed, M. H. Remondin, and E. D. Franco, "Compliance with antimalarial chemoprophylaxis and the subsequent development of malaria: a matched case-control study," The American Journal of Tropical Medicine and Hygiene, vol. 53, no. 5, pp. 511-517, 1995.

[7] P. A. Phillips-Howard, A. Radalowicz, J. Mitchell, and D. J. Bradley, "Risk of malaria in British residents returning from malarious areas," British Medical Journal, vol. 300, no. 6723, pp. 499-503, 1990.

[8] R. H. Behrens and C. F. Curtis, "Malaria in travelers: epidemiology and prevention," British Medical Bulletin, vol. 49, no. 2, pp. 363-381, 1993.

[9] P. A. Phillips-Howard, M. Blaze, M. Hurn, and D. J. Bradley, "Malaria prophylaxis: survey of the response of British travellers to prophylactic advice," British Medical Journal, vol. 293, no. 6552, pp. 932-934, 1986.

[10] H. Kollaritsch and G. Wiedermann, "Compliance of Austrian tourists with prophylactic measures," European Journal of Epidemiology, vol. 8, no. 2, pp. 243-251, 1992.

[11] H. O. Lobel, P. A. Phillips-Howard, A. D. Brandling-Bennett et al., "Malaria incidence and prevention among European and North American travellers to Kenya," Bulletin of the World Health Organization, vol. 68, no. 2, pp. 209-215, 1990.

[12] R. Steffen, R. Heuser, R. Machler et al., "Malaria chemoprophylaxis among European tourists in Africa: use, adverse reactions and efficacy," Bulletin of the World Health Organization, vol. 68, pp. 313-322, 1990. 
[13] Kuwait Demographics Profile 2014, http://www.state.gov/r/pa/ ei/bgn/35876.htm.

[14] Centers for Disease Control and Prevention (CDC), MalariaMalaria and Travelers: Malaria Information and Prophylaxis, by Country, Centers for Disease Control and Prevention, Atlanta, Ga, USA, 2015, http://www.cdc.gov/malaria/travelers/ country_table/k.html.

[15] Ministry of Health, Ports and Borders Health Division Statistics Book 2007-2010, Public Health Department, Ministry of Health, Kuwait City, Kuwait, 2010.

[16] E. van den Enden, "Prevention and Treatment of Malaria," Illustrated lecture notes on Tropical Medicine, Edition 2004, Antwerp, Belgium, 2004, http://itg.author-e.eu/Generated/ pubx/173/illustrated_lecture_notes_on_tropical_medicine.htm.

[17] F. A. Jacquerioz and A. M. Croft, Drugs for Preventing Malaria in Travelers (Review), John Wiley \& Sons, Cochrane Library, 2010, http://www.thecochranelibrary.com/userfiles/ccoch/file/ CD006491.pdf.

[18] J. M. Bissonnette, "Adherence: a concept analysis," Journal of Advanced Nursing, vol. 63, no. 6, pp. 634-643, 2008.

[19] N. Senn, V. D’Acremont, P. Landry, and B. Genton, "Malaria chemoprophylaxis: what do the travelers choose, and how does pretravel consultation influence their final decision," The American Journal of Tropical Medicine and Hygiene, vol. 77, no. 6, pp. 1010-1014, 2007.

[20] WHO, International Travel and Health Book 2012, World Health Organization (WHO), Geneva, Switzerland, 2012.

[21] Kuwait Demographics Profile, 2014, http://www.indexmundi .com/kuwait/demographics_profile.html.

[22] The Demographic Profile of Kuwait, 2015, http://www.escwa.un .org/popin/members/kuwait.pdf.

[23] P. Meankaew, J. Kaewkungwal, A. Khamsiriwatchara, P. Khunthong, P. Singhasivanon, and W. Satimai, "Application of mobiletechnology for disease and treatment monitoring of malaria in the 'Better Border Healthcare Programme,' Malaria Journal, vol. 9, article 237, 2010.

[24] P. Schlagenhauf, A. Tschopp, R. Johnson et al., “Tolerability of malaria chemoprophylaxis in non-immune travellers to subSaharan Africa: multicentre, randomised, double blind, four arm study," British Medical Journal, vol. 327, no. 7423, pp. 10781081, 2003.

[25] E. Petersen, T. Rønne, A. Rønn, I. Bygbjerg, and S. O. Larsen, "Reported side effects to chloroquine, chloroquine plus proguanil, and mefloquine as chemoprophylaxis against malaria in Danish travelers," Journal of Travel Medicine, vol. 7, no. 2, pp. 79-84, 2000.

[26] F. G. J. Cobelens and A. Leentvaar-Kuijpers, "Compliance with malaria chemoprophylaxis and preventative measures against mosquito bites among Dutch travellers," Tropical Medicine and International Health, vol. 2, no. 7, pp. 705-713, 1997.

[27] N. Resseguier, V. MacHault, L. Ollivier et al., "Determinants of compliance with malaria chemoprophylaxis among French soldiers during missions in inter-tropical Africa," Malaria Journal, vol. 9, article 41, 2010.

[28] D. Malvy, T. Pistone, A. Rezvani et al., "Risk of malaria among French adult travellers," Travel Medicine and Infectious Disease, vol. 4, no. 5, pp. 259-269, 2006.

[29] G. Ropers, M. D. R. van Beest Holle, O. Wichmann et al., "Determinants of malaria prophylaxis among German travelers to Kenya, Senegal, and Thailand," Journal of Travel Medicine, vol. 15, no. 3, pp. 162-171, 2008.
[30] H. O. Lobel, M. A. Baker, F. A. Gras et al., "Use of malaria prevention measures by North American and European travelers to East Africa," Journal of Travel Medicine, vol. 8, no. 4, pp. 167-172, 2001.

[31] S. Chatterjee, "Compliance of malaria chemoprophylaxis among travelers to India," Journal of Travel Medicine, vol. 6, no. 1, pp. 7-11, 1999.

[32] R. H. Behrens, R. B. Taylor, D. I. Pryce, and A. S. Low, "Chemoprophylaxis compliance in travelers with malaria," Journal of Travel Medicine, vol. 5, no. 2, pp. 92-94, 1998.

[33] P. Landry, D. Iorillo, R. Darioli, M. Burnier, and B. Genton, "Do travelers really take their mefloquine malaria chemoprophylaxis? Estimation of adherence by an electronic pillbox," Journal of Travel Medicine, vol. 13, no. 1, pp. 8-14, 2006.

[34] O. P. Gagneux, C. U. Blöchliger, M. Tanner, and C. F. Hatz, "Malaria and casual sex: what travelers know and how they behave," Journal of Travel Medicine, vol. 3, no. 1, pp. 14-21, 1996. 


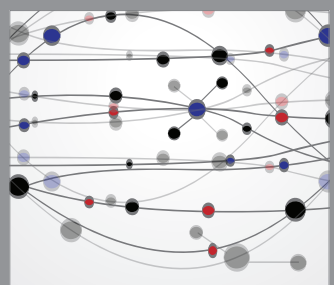

The Scientific World Journal
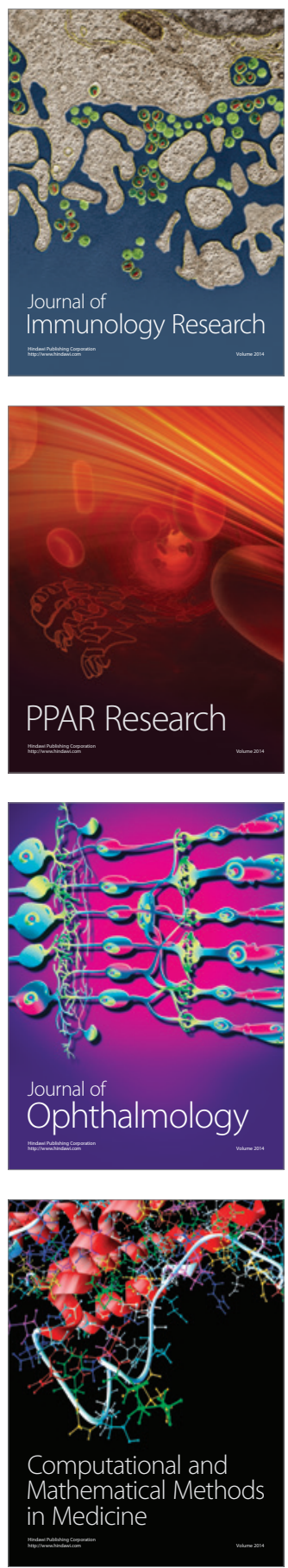

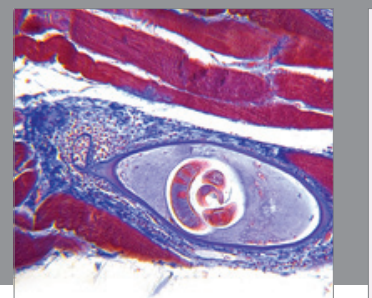

Gastroenterology

Research and Practice
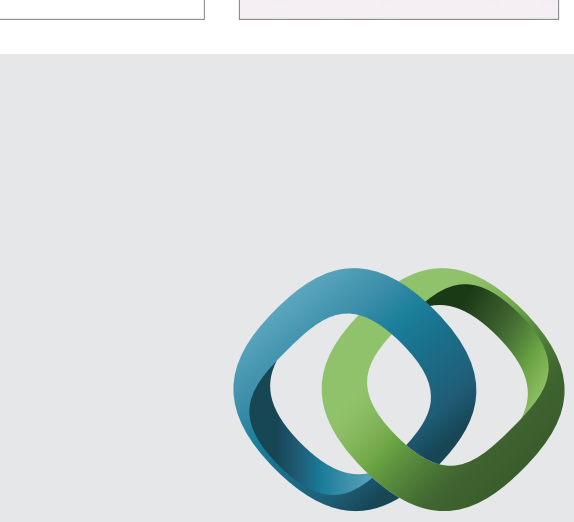

\section{Hindawi}

Submit your manuscripts at

http://www.hindawi.com
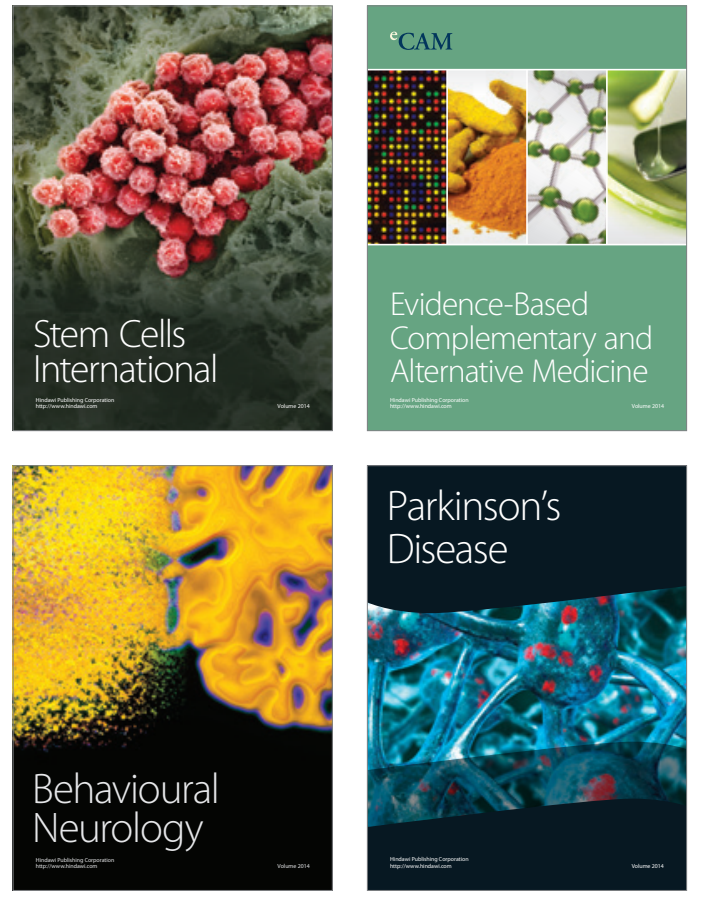
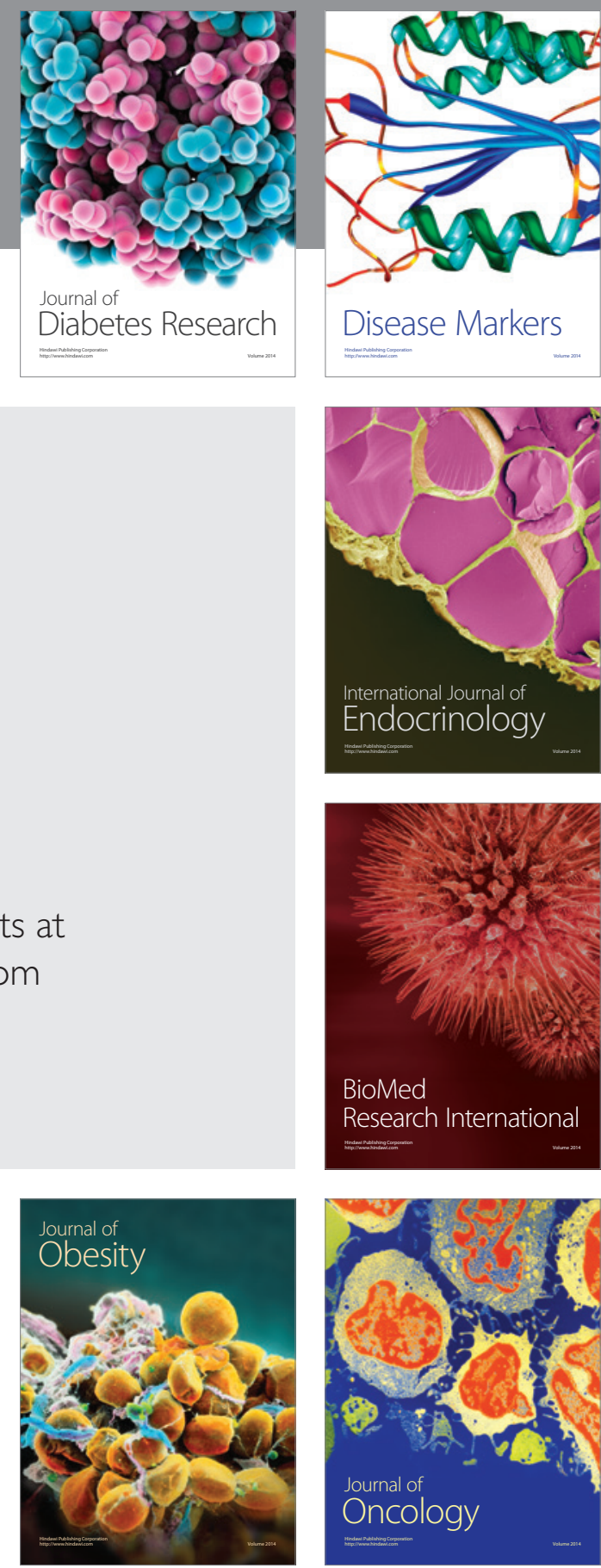

Disease Markers
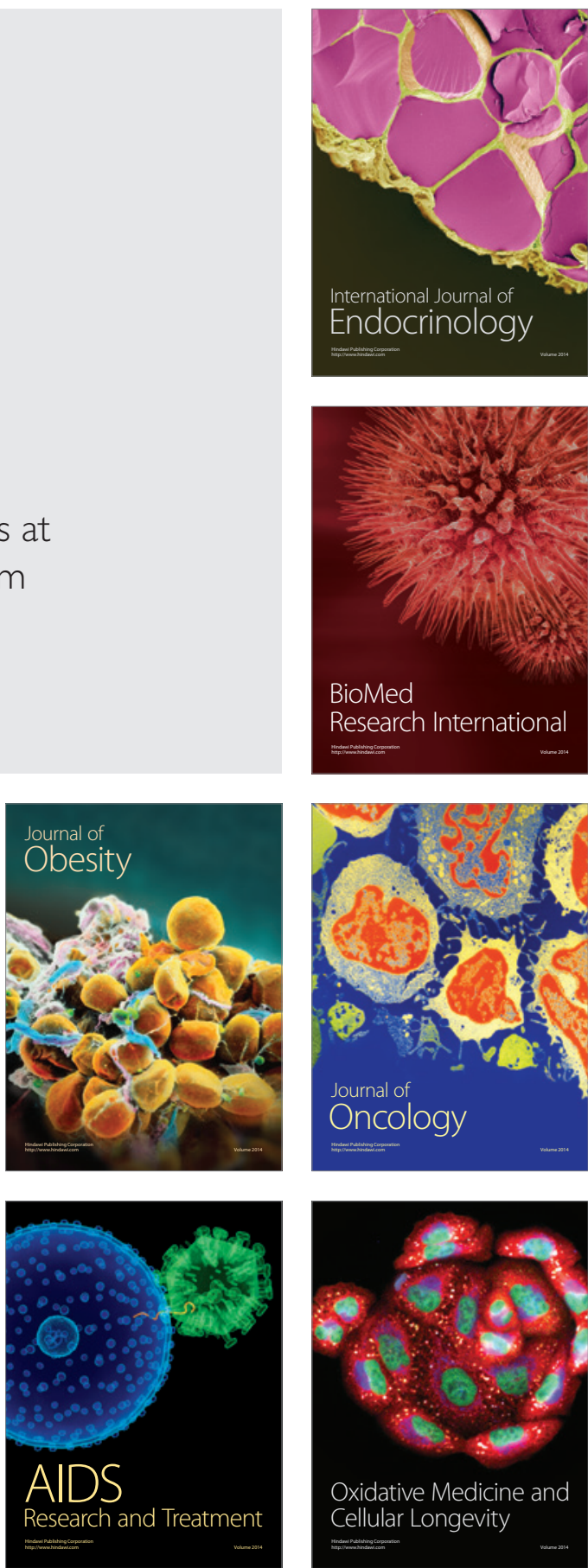